This item was submitted to Loughborough's Research Repository by the author.

Items in Figshare are protected by copyright, with all rights reserved, unless otherwise indicated.

\title{
Characterisation of mechanical behaviour and damage analysis of 2D woven composites under bending
}

PLEASE CITE THE PUBLISHED VERSION

http://dx.doi.org/10.1016/j.compositesb.2015.01.036

\section{PUBLISHER}

(C) Elsevier Ltd

\section{VERSION}

AM (Accepted Manuscript)

\section{PUBLISHER STATEMENT}

This work is made available according to the conditions of the Creative Commons Attribution-NonCommercialNoDerivatives 4.0 International (CC BY-NC-ND 4.0) licence. Full details of this licence are available at: https://creativecommons.org/licenses/by-nc-nd/4.0/

\section{LICENCE}

CC BY-NC-ND 4.0

\section{REPOSITORY RECORD}

Ullah, Himayat, Andy Harland, and Vadim Silberschmidt. 2015. "Characterisation of Mechanical Behaviour and Damage Analysis of 2D Woven Composites Under Bending”. Loughborough University. https://hdl.handle.net/2134/16972. 


\title{
Characterisation of mechanical behaviour and damage analysis of 2D woven composites under bending
}

\author{
Himayat Ullah ${ }^{1}$, Andy R. Harland, Vadim V. Silberschmidt* \\ Wolfson School of Mechanical and Manufacturing Engineering, Loughborough University, Ashby Road, Loughborough, Leicestershire, LE11 3TU, UK
}

Keywords:

A. Fabrics

B. Damage tolerance

D. Mechanical testing

C. Finite element analysis

\begin{abstract}
a b s t r a c t
In this paper, flexural loading of woven carbon fabric-reinforced polymer laminates is studied using a combination of experimental material characterisation, microscopic damage analysis and numerical simulations. Mechanical behaviour of these materials was quantified by carrying out tensile and largedeflection bending tests. A substantial difference was found between the materials' tensile and flexural properties due to a size effect and stress stiffening of thin laminates. A digital image-correlation technique capable of full-field strain-measurement was used to determine in-plane shear properties of the studied materials. Optical microscopy and micro-computed tomography were employed to investigate deformation and damage mechanisms in the specimens fractured in bending. Various damage modes such as matrix cracking, delaminations, tow debonding and fibre fracture were observed in these microstructural studies. A two-dimensional finite-element (FE) model was developed to analyse the onset and propagation of inter-ply delamination and intra-ply fabric fracture as well as their coupling in the fractured specimen. The developed FE model provided a correct prediction of the material's flexural response and successfully simulated the sequence and interaction of damage modes observed experimentally.
\end{abstract}

\section{Introduction}

Carbon fabric-reinforced polymer (CFRP) composites have found a wide range of application in aerospace, automotive structures and sports products due to their high specific stiffness and strength. Fabric-reinforced composites offer better fracture toughness and resistance to damage, particularly delamination, due to their weaving architecture as compared to that of unidirectional tape laminates [1]. Composite structures such as aircraft wings, automotive bumpers and sports products, e.g. a sole of a sports shoe, tennis rackets and bicycle components can be subjected to large-deflection bending during their service. Under such loading conditions, characterisation of the mechanical behaviour of woven composites is necessary to evaluate their structural performance, provide data for analysis and design of composite laminates and understand their response to different loading conditions. In

\footnotetext{
* Corresponding author. Tel.: p44 1509 227504; fax: p44 1509227502. E-mail addresses: uhimayat@gmail.com (H. Ullah),V.Silberschmidt@lboro.ac.uk (V.V. Silberschmidt).

${ }^{1}$ Present address: National University of Sciences and Technology, College of E\&ME, Peshawar Road, Islamabad, Pakistan.
}

addition, these properties are fundamental for development of numerical models used to analyse deformation and fracture of composites at various structural levels. The experimental characterisation is based on determination of material's behaviour and properties by means of mechanical tests on suitable specimens performed for different orientations due to anisotropy of composites. A significant amount of information has been acquired in the literature on mechanical properties of CFRP woven composites concerning their stiffness, strength and toughness [2e5]. However, most experimental work has been concerned with their tensile behaviour while the large-deflection flexure is rarely studied. Despite the known discrepancy in tensile and flexural data for composites, the tensile data are still usually used for the design of composite structures experiencing bending loads. Further, composites demonstrate variation in their mechanical properties with their size and volume [6], which makes it necessary to test specimens of specific size to get the accurate material's data for their particular end use.

Despite a continuously increasing number of their applications, one of the major concerns of composite materials is damage induced in service of a structure subjected to various loading scenarios. Damage in composites causes a substantial reduction in 
their strength and stiffness, degrading the load-carrying capability of the structures. Besides, damage patterns in woven composites are more complicated than in UD laminates at various length scales due to the variability and complexity of their microstructure [3]. Therefore, it is of paramount importance to identify and investigate main damage mechanisms in woven composite structures for their damage-tolerant design and development of modelling tools capable of predicting these failures. Microstructural damage mechanisms such as matrix cracking, delamination, fibre fracture and tow debonding induced by static and dynamic loading are often barely visible and cannot be detected by simply examining the exposed surfaces of composite specimens. The traditional nondestructive damage-assessment techniques such as ultrasonic Cscan [7], X-ray radiography and thermography are efficient for providing detailed information of damage area, yet they are limited in their resolution and ability to track the interaction of various damage modes. Destructive schemes such as de-ply technique and serial sectioning of specimens followed by microscopy can provide very detailed characterisation of damage. Additionally, all these techniques provide damage information for materials in 2D crosssections of their surfaces, limiting characterisation of inherently 3D internal damage processes within the composite laminate. This shortcoming can be overcome with the use of X-ray microcomputed tomography (micro-CT), which can provide 3D images of internal damage mechanisms and their interaction in composites. The micro-CT technique was employed in Refs. [8e10] to analyse damage behaviour of composites at a micron scale. Several studies can be found on the investigation of damage in composites subjected to tensile loadings [11,12]. However, damage of woven composites under large bending deformation is rarely studied; thus, more research work is required for better understanding of such damage phenomena.

This paper presents details of the experimental methods for characterisation of stiffness and strength properties of CFRP laminates in various directions under quasi-static tensile and largedeflection flexural loading regimes. The bending tests were also carried out at low strain rates to investigate the strain-rate sensitivity of on-axis laminates. Specimens of various thicknesses were tested to investigate the size effect on their mechanical behaviour. Shear properties of the material were determined from the fullfield strain analysis obtained with the digital image-correlation (DIC) technique. In the authors' view, for the first time, microstructural damage examination of CFRP specimens tested under large-deflection bending was carried out with optical microscopy and micro-CT scanning. The damage evaluation capabilities of both techniques were also compared. Based on the damage analyses, some of the observed damage mechanisms such as delamination, fabric fracture and their interaction were elaborated in the developed FE model.

\section{Experimental procedures}

\subsection{Material systems}

The materials studied were laminates of woven fabric made of carbon fibres reinforcing a thermoplastic polyurethane (TPU) polymer matrix. The TPU resin is a tough polymer providing a better resistance to impact and fatigue, making it favourable for applications demanding energy absorption especially in sports products. The specimens were produced from $0^{\circ} / 90^{\circ}$ prepregs in the form of six and four plies designated as $\left[0^{\circ}, 90^{\circ}\right]_{3 \mathrm{~s}}$ and $\left[0^{\circ}, 90^{\circ}\right]_{2 \mathrm{~s}}$, respectively. In this study, the stacking orders of the form $\left[0^{\circ}, 90^{\circ}\right]_{3 \mathrm{~s}}$ and $\left[0^{\circ}, 90^{\circ}\right]_{2 \mathrm{~s}}$ are designated as warp specimens, whereas $\left[90^{\circ}, 0^{\circ}\right]_{3 \mathrm{~s}}$ and $\left[90^{\circ}, 0^{\circ}\right]_{2 s}$ as weft specimens. All the woven laminates had a $2 / 2$ twill 2D symmetric and orthogonal weaving pattern. The internal architecture of the fabric tows has a significant effect on mechanical properties and damage behaviour of woven composites. As damage is sensitive to geometrical parameters of woven laminates such as the size and location of tows and resin within the laminate, thus, cross-sections of the laminate at various locations showing dimensions of tows and inter-ply resin-rich regions are illustrated in Fig. 1. From the measurements of the tow dimensions at different locations of the specimen, it can be seen that the $2 / 2$ twill weave weft tow has an elliptical shape, with major and minor diameters of $1.78 \pm 0.08 \mathrm{~mm}$ and $0.142 \pm 0.005 \mathrm{~mm}$, respectively. The thickness of the resin-rich interface between two plies varied from 15 to 17 microns. It was also observed with optical microscopy and micro-CT of the specimens that the ends, i.e. a number of tows in the warp direction, was 5.2 per $\mathrm{cm}$ whereas the picks, i.e. a number of tows in the weft direction, was 5.14 per $\mathrm{cm}$. Due to this minor difference in the counts of ends and picks, the numbers of tows in the warp and weft specimens along their longitudinal plane are 13 and 12.85, respectively, based on $25 \mathrm{~mm}$ width of the specimens tested. The detailed parameters of the twill woven CFRP composites are given in the authors' work [10].

In this work, three types of fabric-reinforced CFRP specimens were experimentally tested. The two main on-axis specimens, used in tensile and flexural tests, were laminates of $1.5 \mathrm{~mm}$ and $1 \mathrm{~mm}$ thickness with six and four plies, respectively. The third type of CFRP specimens was the off-axis $[p 45 /-45]_{4 s}$ 2D woven laminate of $2 \mathrm{~mm}$ thickness consisting of 8 plies; tested to determine inplane shear properties of the material. Here, flat rectangular specimens of $80 \mathrm{~mm}$ length and $25 \mathrm{~mm}$ width cut and ground to remove notches and rough edges were used for tensile testing. The Labtom cut off wheel, with a water cooled diamond cutting wheel was used, providing good surface quality of the samples. In all the tensile and flexural tests, except in-plane shear tests, the specimens for both the warp and weft orientations had the same length and width as advised by the respective standards.

\subsection{Tensile tests}

In this study, all the tensile tests were performed on the Instron 5569 machine in accordance with the ISO 527-4/5 standard. The tests were conducted on $1.5 \mathrm{~mm}$ thick warp and weft specimens with displacement control at a jaw speed of $100 \mathrm{~mm} / \mathrm{min}$, which was equivalent to the strain rate of $0.0417 \mathrm{~s}^{-1}$. This strain rate was
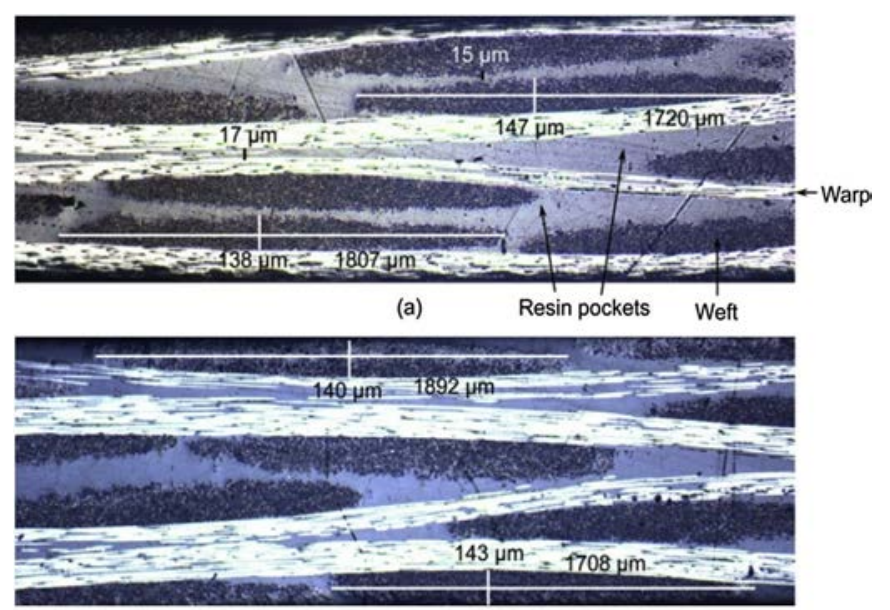

(b)

Fig. 1. Through-thickness micrographs showing dimensions of weft tows and resin thickness measured at tows in resin-rich region (a) and surface (b) of on-axis 4-ply CFRP laminate. 
used for comparability of the tensile-test results with those of flexural tests carried out at similar strain rates as described in Section 2.4.1. End tabs of the same material and orientation as that of the tensile specimen were adhesively bonded to the ends of the specimen. To avoid errors in the load-cell reading of displacements and strains due to the possibility of slippage of CFRP specimens in the grips, an extensometer capable of $25 \mathrm{~mm}$ extension was used for accurate strain measurement. Five samples having a gauge length of $40 \mathrm{~mm}$ for both warp and weft orientations were tested until fracture. Tensile strength, elongation and the elastic modulus, determined from the data according to ISO 527-1, are presented in Table 1. Although the focus of this study was on the mechanical behaviour of woven composites under large-deflection bending, the tensile tests were conducted to compare their tension behaviour to the flexural one. Still, in most studies, material properties obtained through tensile tests are used for the flexure behaviour; the validity and comparison of this approach is discussed in Section 2.4.2.

As shown in Table 1, the tensile tests resulted in approximately the same magnitudes of elastic moduli and ultimate tensile strengths for the warp and weft specimens. This similarity is due to the small difference in ends/picks count in both types of specimens. In fibre-reinforced polymer composites, the axial tensile strength is sensitive to the fibre alignment with respect to the direction of applied load. This anisotropic behaviour of the material is dictated by orientation of fibres, affecting the load-sharing mechanism. In on-axis laminates, where the fibres are aligned along $0^{\circ} / 90^{\circ}$, the fibres take the maximum load, and the specimen exhibits high strength at fracture associated with low ductility. In contrast, the TPU polymer matrix has lower strength than the reinforcing carbon fibres. When the fibres fail at the ultimate strength, the polymer matrix is incapable to bear the applied load, and, thus, catastrophic specimen failure occurs suddenly. However, in off-axis laminates, where the fibres are oriented at various angles, e.g. $\pm 45^{\circ}$, with respect to the tensile loading direction, the applied load is resolved into longitudinal and transverse components, thus developing shear flow in the matrix even at low tensile loads [13], which can be observed in the next section.

\subsection{In-plane shear tests}

In-plane shear properties of the studied materials such as shear modulus, Poisson's ratio and shear strength were determined by conducting tensile tests for $\pm 45^{\circ}$ woven CFRP specimens according to ASTM D3518 standard. Here, an ARAMIS digital imagecorrelation (DIC) system was used to obtain the full-field in-plane strain data. Before testing, the specimens were marked with black spots after spraying them with white paint to provide contrast necessary for image correlation. The tests were conducted on the Instron 5569 machine; with two high-speed 1 megapixel digital cameras taking images of the stretched specimen at frequency of 50 frames per second. Load measurements of the Instron machine were synchronised with images for each time interval. Rectangular CFRP specimens of size $200 \mathrm{~mm} \times 25 \quad \mathrm{~mm} \quad \mathrm{x} \quad 2 \quad \mathrm{~mm}$ (length $x$ width $x$ thickness) made of $[p 45 /-45]_{4 s}$ layups were tested at a crosshead speed of $10 \mathrm{~mm} / \mathrm{min}$ equivalent to a strain rate

Table 1

Tensile test data of CFRP specimens.

\begin{tabular}{llll}
\hline Laminate orientation & $\begin{array}{l}\text { Ultimate tensile } \\
\text { strength }(\mathrm{MPa})\end{array}$ & Elongation (\%) & Elastic modulus (GPa) \\
\hline Warp, $\left[0^{\circ}, 90^{\circ}\right]_{3 \mathrm{~s}}$ & $762.0 \pm 12.0$ & $1.55 \pm 0.05$ & $48.6 \pm 1.3$ \\
Weft, $\left[90^{\circ}, 0^{\circ}\right]_{3 \mathrm{~s}}$ & $764.0 \pm 10.0$ & $1.56 \pm 0.06$ & $49.4 \pm 1.2$
\end{tabular}

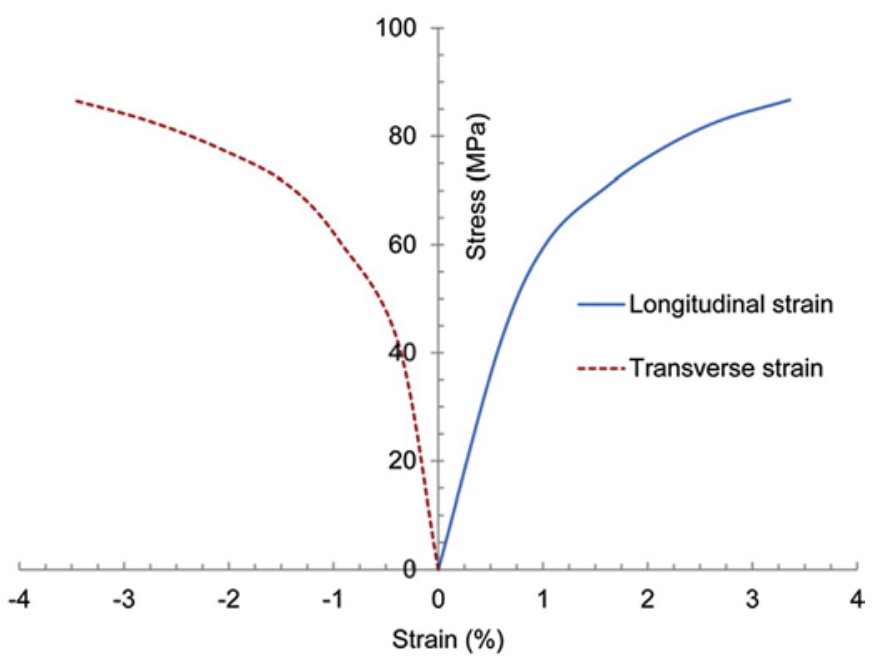

Fig. 2. Longitudinal stress versus longitudinal and transverse strain from digitally imaged tensile test of $[\mathrm{p} 45 /-45]_{2 \mathrm{~s}}$ twill $2 / 2$ woven CFRP specimen.

of $0.0041 \mathrm{~s}^{-1}$. The material's in-plane shear modulus $\mathrm{G}_{12} \quad 1 / 43.8 \mathrm{GPa}$ was determined from the obtained shear stressestrain curve in its linear-elastic range. A dependence of longitudinal stress on transverse and longitudinal strains is plotted in Fig. 2; it was used to determine the material's in-plane Poisson's ratio $n_{12}^{1 / 4} 0.05$ in the linear range. The nominal dependence of tensile stress on longitudinal (major) strain, with strain levels determined using the DIC method, shown in Fig. 3, exhibited a nonlinear behaviour, which might be due to matrix plasticity and cracking as well as alignment of tows along the loading directions (fibre trellising). As the tows were oriented at $\pm 45^{\circ}$ with respect to the tensile axis, the applied load induced substantial plastic deformation in the compliant TPU matrix even at low tensile load levels. Contour plots of major (longitudinal), minor (transverse) and shear strains obtained from the digitally imaged tensile tests of the off-axis CFRP specimen at the applied tensile stresses of $100 \mathrm{MPa}, 150 \mathrm{MPa}, 200 \mathrm{MPa}$ and $250 \mathrm{MPa}$ corresponding to positions 'g', 'h', 'i' and 'j' in Fig. 3 are shown in Figs. 4e7, respectively. The load level of $250 \mathrm{MPa}$ is the maximum applied load just before the specimen's ultimate fracture. It is apparent from these figures that strain contours for the

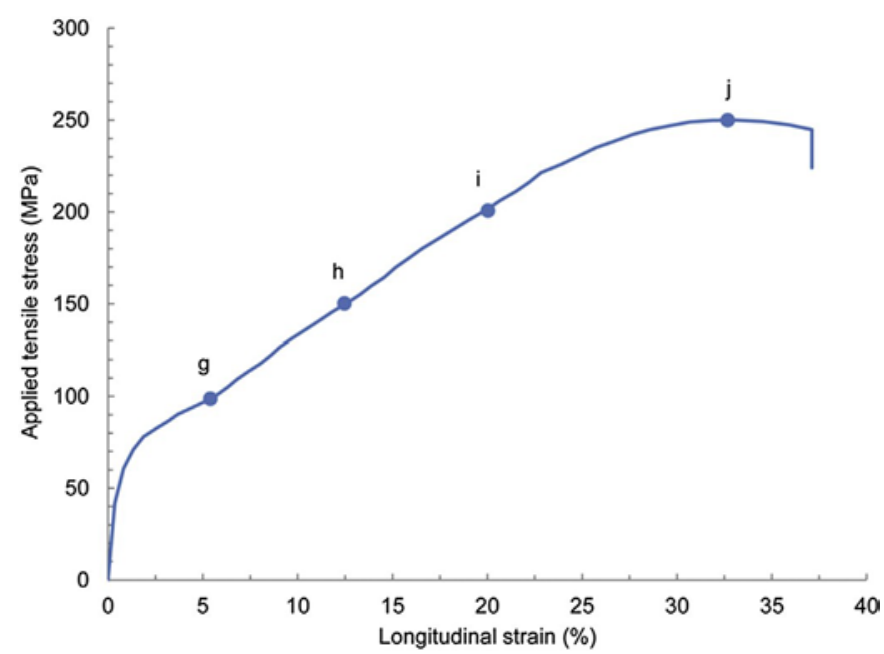

Fig. 3. Tensile stressestrain curve of $[\mathrm{p} 45 /-45]_{4 \mathrm{~s}}$ CFRP determined using the DIC system indicating the positions ' $g$ ', ' $h$ ', ' $i$ ' and ' $j$ ' taken for the strain contour plots in Figs. 4e7, respectively. 


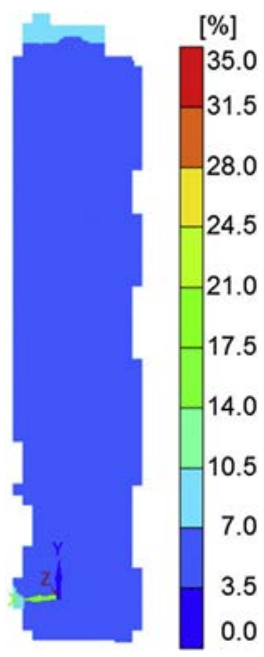

(a)

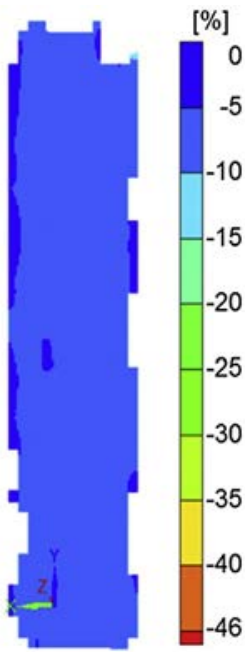

(b)

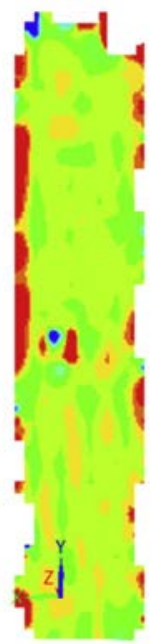

(c)
Fig. 4. Contour plots of major (a), minor (b) and shear (c) strains from $[p 45 /-45]_{4}$ CFRP tensile test at stress level of $100 \mathrm{MPa}$ corresponding to point ' $\mathrm{g}$ ' indicated in Fig. 3.

major, minor and shear plots vary due to the material's heterogeneity and anisotropy. Here, the major and minor strain contour plots are almost homogeneous due to symmetry of tows in p45/ -45 orientations at lower applied loads (Figs. 4 and 5). However, with the increasing applied load, the localised plastic flow behaviour of the matrix and fibre trellising is reflected in heterogeneous strain contours in the form of high-strain regions in the strain maps shown in Figs. 6 and 7. The missing parts of the images represent the areas of paint flaking, which was speckled, and thus the data at these regions was not collected.

\subsection{Bending tests}

Since the focus of this study is on characterisation of the material's behaviour under the complex state of flexural as well as shear stresses, three-point bending tests are a reasonable choice. As compared to tensile tests, a complex stress state is experienced by

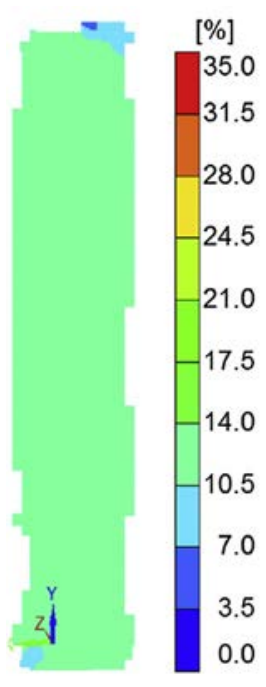

(a)

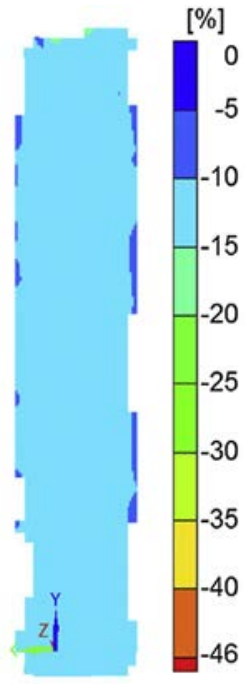

(b) (c)

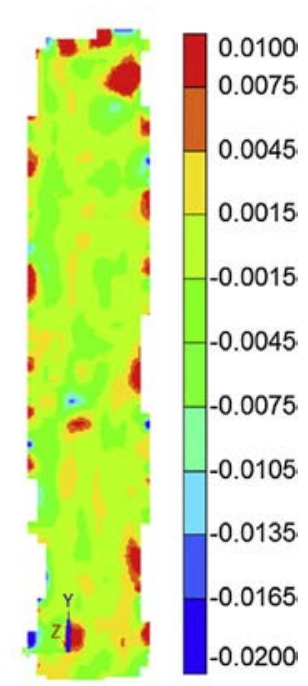

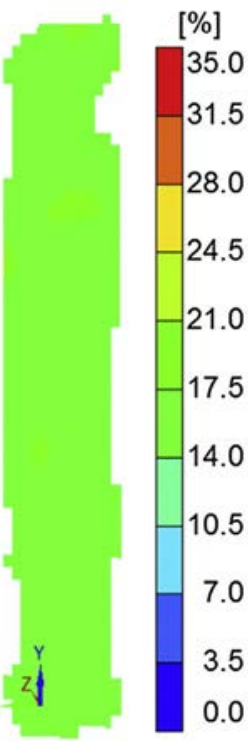

(a)

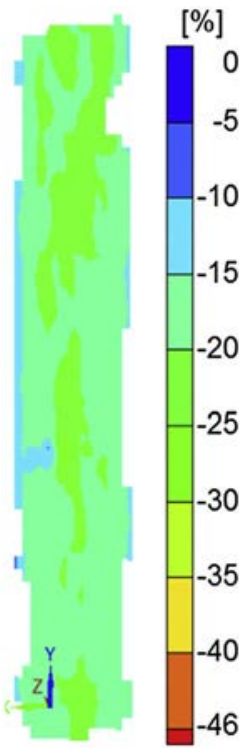

(b)

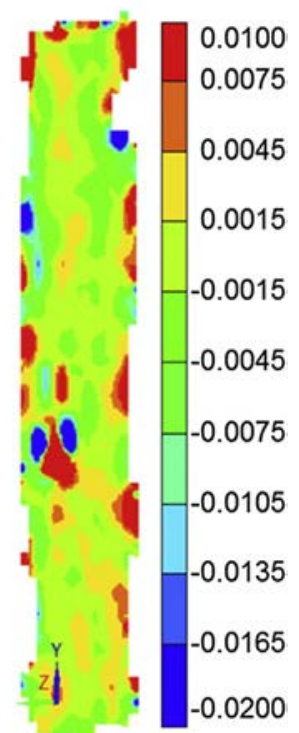

(c)
Fig. 6. Contour plots of major (a), minor (b) and shear (c) strains from $[p 45 /-45]_{4 \mathrm{~s}}$ CFRP tensile test at stress level of $200 \mathrm{MPa}$ corresponding to point ' $\mathrm{i}$ ' indicated in Fig. 3.

composites in flexural tests, with tensile, compressive and shear stresses present simultaneously in a loaded specimen. Therefore, it is typically difficult to relate directly the obtained flexural properties to tensile, compressive and shear properties of the material. Further, analysis of bending-test results for anisotropic materials is more complicated than that for the uniaxial tensile test. Still, this loading type is particularly relevant as various composite structures are subjected to flexural loading in service. Due to the important influence of shear effects on displacements, large span-to-thickness

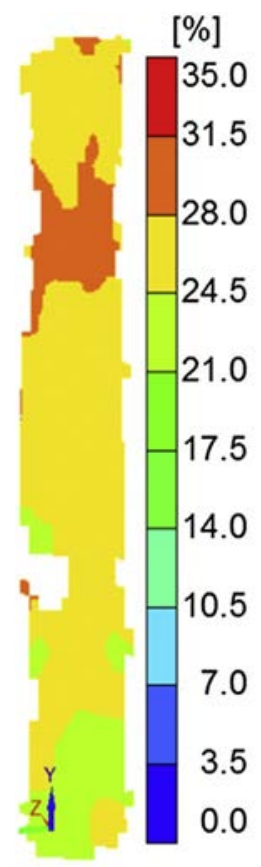

(a)

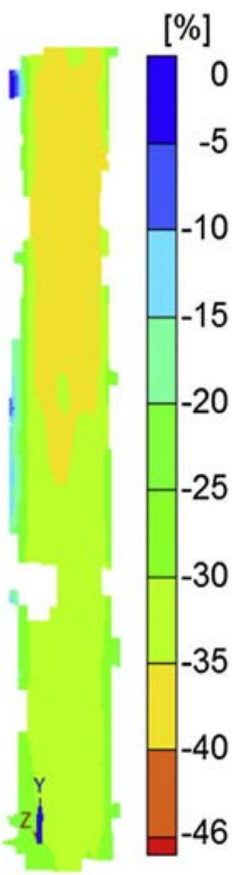

(b)

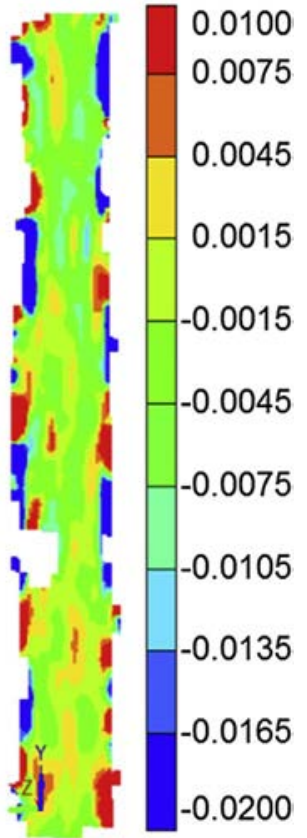

(c)
Fig. 7. Contour plots of major (a), minor (b) and shear (c) strains from $[p 45 /-45]_{4 \mathrm{~s}}$ CFRP tensile test at stress level of $250 \mathrm{MPa}$ corresponding to point ' $\mathrm{j}$ ' indicated in Fig. 3. 


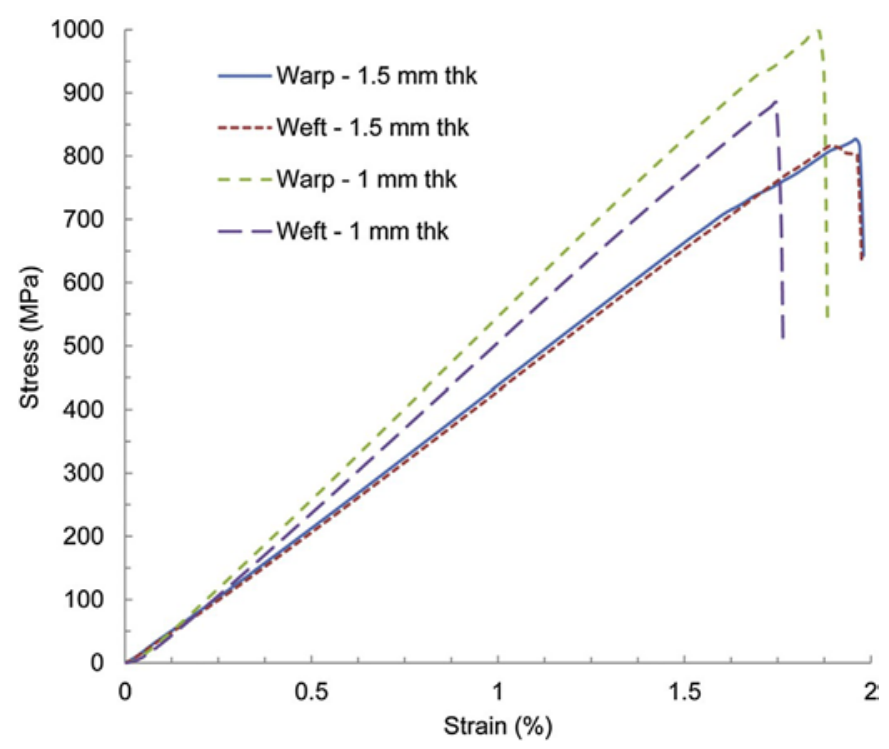

Fig. 8. Stress-strain diagram from flexural tests of 1.5 and $1.0 \mathrm{~mm}$ thick twill $2 / 2$ CFRP specimens.

ratios of specimens were used in the tests to eliminate these effects. In composite laminates, the stiffness of each ply can be different because of different fibre orientations. Therefore, the laminatedbeam theory yields in a discontinuous distribution of normal stresses across the specimen's thickness, even though the strain variation is linear. Through thickness of a single ply, the stress varies linearly, exhibiting discontinuities at ply boundaries. For bending tests of composites, the maximum flexural stresses occurring at the top and bottom plies of the specimen are determined, for which the simple homogeneous beam theory is a reasonable choice, as employed in the flexure-test standard for composites [14]. From the simple-beam theory, the tensile and compressive flexural stresses at the surfaces of specimen, where the bending moment is maximal, can be found using:

$\mathrm{S}_{\mathrm{x}} 1 / 4 \frac{\mathrm{M}_{\mathrm{my}}}{\mathrm{I}}$

where $M_{m} 1 / 4 \frac{F_{m} S}{4}$ is the maximum bending moment at the beam's mid-span in three-point bending, $\mathrm{y}^{1 / 4} \frac{\mathrm{h}}{2}$ is the distance from the neutral axis to the specimen's surface, $\mathrm{S}$ is the span between the supports and $\mathrm{I}^{1 / 4} \frac{\mathrm{bl}^{3}}{12}$ is the moment of inertia of the specimen's

rectangular cross section; $\mathrm{b}$ and h are the specimen's width and thickness, respectively. This simple-beam formula is based on the assumption that deflection is small in comparison with the span. When deflections are large, as in the case for long beams, Eq. (1) for stress is corrected, as discussed in ASTM D 790 [14]. The standard recommends that if the support span-to-thickness ratios greater than 16 are used such that deflections in excess of $10 \%$ of the support span occur, the stress in the outer layer of the specimen for a simple beam can be reasonably approximated with the following equation:
$\mathrm{S}_{\operatorname{corr} 1 / 4} \mathrm{~S}_{\mathrm{x}} 1 \mathrm{p} 6 \frac{\mathrm{d}^{2}}{\mathrm{~S}}-4 \frac{\mathrm{h}}{\mathrm{S}} \frac{\mathrm{d}}{\mathrm{S}}$;

where $d$ is the maximum deflection of the specimen. This equation also takes into account additional bending moments due to horizontal components of the support reactions in case of largedeflection bending.

\subsubsection{Testing procedure}

Two types of specimens of $80 \mathrm{~mm}$ length and $25 \mathrm{~mm}$ width were prepared with thicknesses of $1.5 \mathrm{~mm}$ and $1 \mathrm{~mm}$ to observe the effect of thickness on flexural properties of CFRP. The loading span between the supports was kept at $40 \mathrm{~mm}$ in all the three-point bending tests. The bending tests were performed at indenter speed of $100 \mathrm{~mm} / \mathrm{min}$ equivalent to the strain rate $0.0417 \mathrm{~s}^{-1}$, using the Instron 5569 machine according to ASTM D790 standard [14]. Five specimens for each layup configuration were tested under large-deflection bending until their ultimate fracture; the tests were performed in the displacement-control regime. The data was recorded by the machine load cell in the form of applied load and deflection of the specimen. Since in this study the support span-tothickness ratios were 26.7 and 40 for specimens with thickness of $1.5 \mathrm{~mm}$ and $1 \mathrm{~mm}$, respectively, and also the maximum deflection $d$ was greater than $10 \%$ of span S, so Eq. (2) was used to determine flexural stress. Similarly, the flexural modulus and the maximum flexural strain were determined according to ASTM D790 standard.

\subsubsection{Discussion of flexural-test results}

The flexural stress-strain diagrams for each orientation of CFRP specimens of $1.5 \mathrm{~mm}$ and $1.0 \mathrm{~mm}$ thickness are shown in Fig. 8. In both types of specimens, flexural tests of warp and weft on-axis laminates demonstrated a quasi-brittle behaviour. The reason for this material behaviour is that in on-axis laminates, the applied load is carried by the fibres, which are strong but brittle. Thus, the stress-strain curves are almost linear up to catastrophic failure, represented by an abrupt drop of the stress level in Fig. 8. As presented in Table 2, the flexural tests resulted in slightly different elastic moduli and flexural strengths in both warp and weft directions for each type of specimens because of the little difference in the ends/pick count of the fabric structure. In 2D woven laminates, the tows are undulated and have crimps. When loaded in tension due to bending, each layer of the laminate tended to have out-of-plane deformation, with a 3D stress state resulting in earlier damage initiation at the crimp locations. The damage then propa-

gated to resin-rich pockets around the tows and delamination between tows and longitudinal cracking in weft tows occurred as observed in Fig. 10. The weft tow cracking (intra-tow damage) began early in the loading process and almost all weft yarns possessed this kind of damage before the final fracture of the laminate. However, the stress-strain curve exhibited a linear trend (see Figs. 8 and 9), as the effect of these damage mechanisms was small and the main load-bearing components were warp tows aligned to the loading direction. However, stiffness degradation occurred at $90 \%$ of the ultimate load in the wrap specimens,

Table 2

Flexural test data of CFRP specimens.

\begin{tabular}{|c|c|c|c|c|c|}
\hline Thickness (mm) & Orientation & Flexural modulus (GPa) & Ultimate flexural strength (MPa) & Maximum deflection (mm) & Elongation (\%) \\
\hline \multirow[t]{2}{*}{1.5} & Warp, $\left[0^{\circ}, 90^{\circ}\right]_{3 \mathrm{~s}}$ & $44.1 \pm 1.3$ & $826.0 \pm 22$ & $3.64 \pm 0.22$ & $1.96 \pm 0.08$ \\
\hline & Weft, $\left[90^{\circ}, 0^{\circ}\right]_{3 \mathrm{~s}}$ & $43.6 \pm 1.2$ & $816.0 \pm 20$ & $3.6 \pm 0.2$ & $1.90 \pm 0.1$ \\
\hline \multirow[t]{2}{*}{1.0} & Warp, $\left[0^{\circ}, 90^{\circ}\right]_{2 \mathrm{~s}}$ & $55.0 \pm 1.5$ & $993 \pm 25$ & $5.1 \pm 0.3$ & $1.85 \pm 0.07$ \\
\hline & Weft $\left[90^{\circ}, 0^{\circ}\right]_{2 \mathrm{~s}}$ & $52.0 \pm 1.4$ & $885 \pm 23$ & $4.75 \pm 0.26$ & $1.76 \pm 0.06$ \\
\hline
\end{tabular}




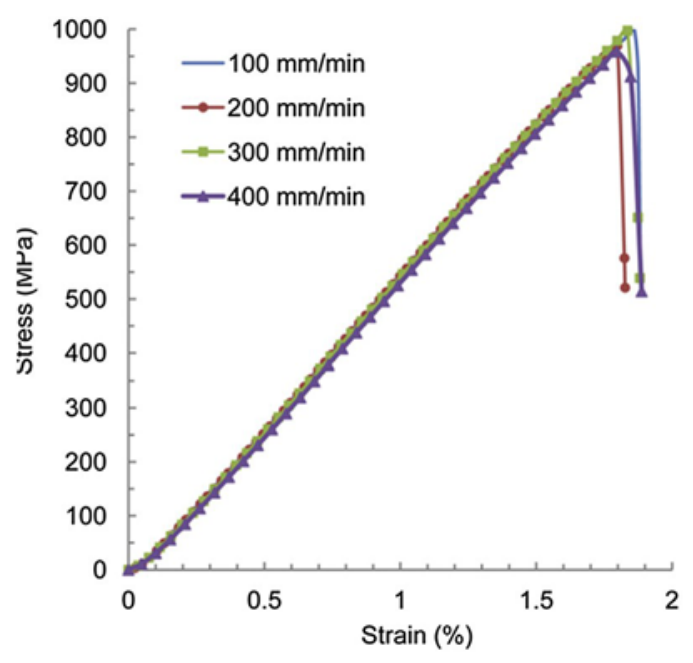

(a)

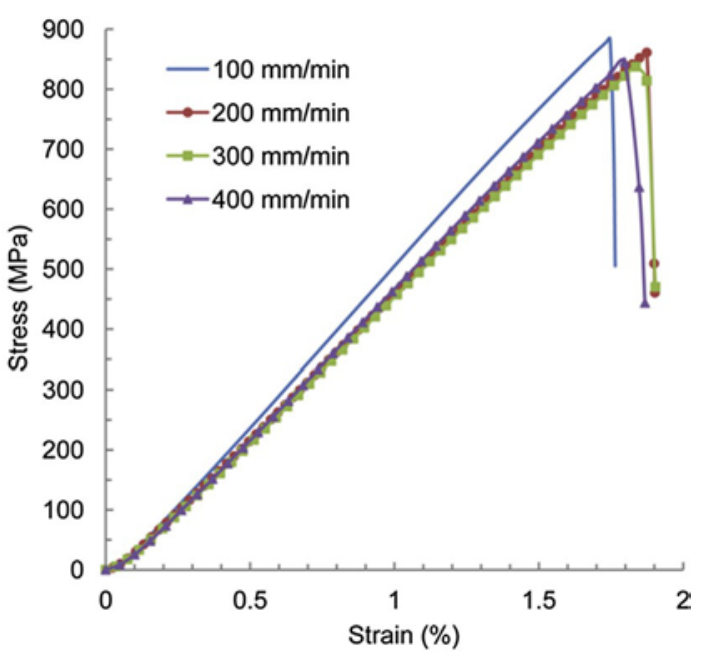

(b)

Fig. 9. Flexural behaviour of $1.0 \mathrm{~mm}$ thick warp (a) and weft (b) specimens at various test speeds.

whereas the weft laminates showed no stiffness reduction before ultimate fracture (Fig. 8). As described in Section 2.1, the number of tows/fibres along the longitudinal plane in warp specimens was a little more than that of weft specimens, thus the warp specimens resisted the bending load slightly more than the weft ones. As the load was increased, the crimped tows below the specimen's neutral plane subjected to tension tried to straighten along the loading direction, which was prevented by the tows in the transverse direction resulting in an increasing composite stiffness and ultimate strain as elaborated in Ref. [15]. At still higher loads, one or more aligned stiff tows ruptured earlier, at about $90 \%$ of the ultimate load, causing the load drop before catastrophic failure of the warp specimens (see the stress-strain curve in Fig. 8). This progressive fibre/tow rupture with increasing load can also be observed in the staggered failure pattern of tows shown in Fig. 10b. On the contrary, the weft specimens with a lower number of fibres/tows aligned to the loading direction (see Fig. 8 and Table 2) did not exhibit such behaviour; here, all the highly stressed tows failed simultaneously at a lower load level resulting in the ultimate fracture of the weft specimen.

The elastic flexural moduli such as $E_{11}$ and $E_{22}$ were determined from the bending tests of both types of specimens in the warp and

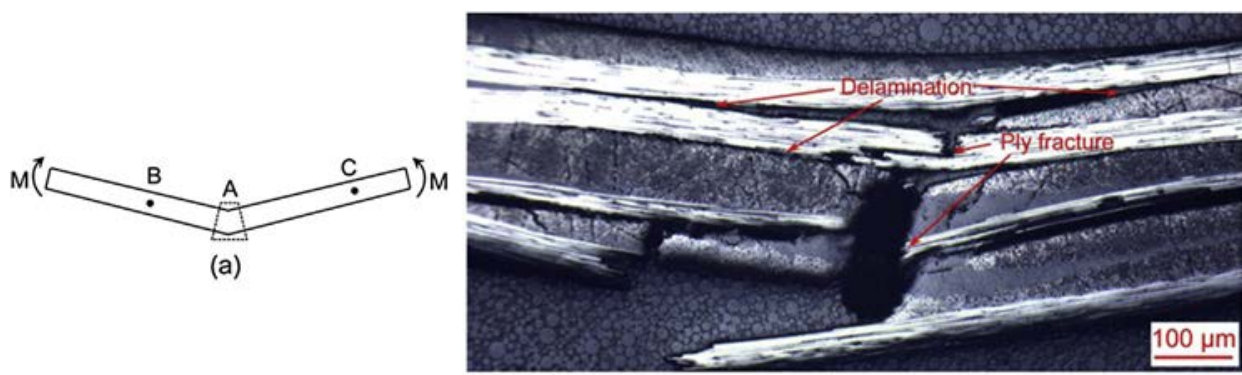

(b)

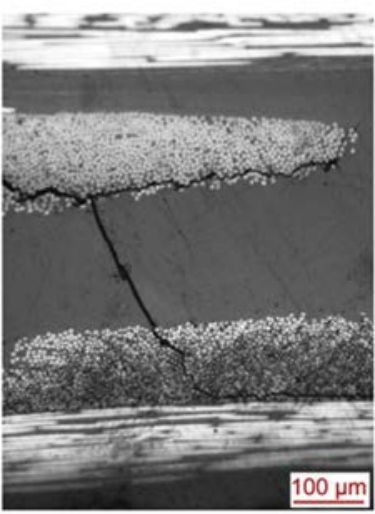

(c)

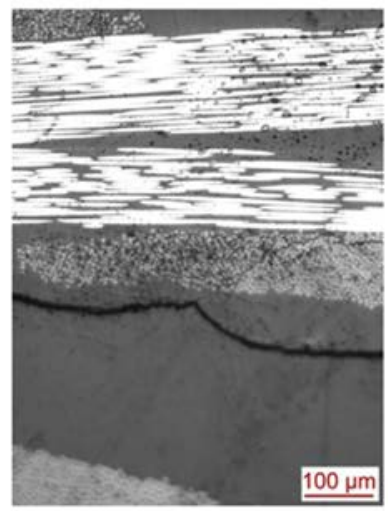

(d)

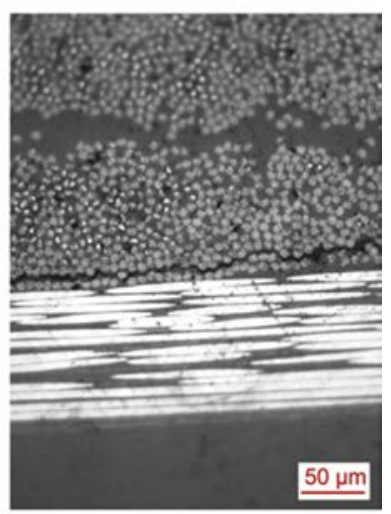

(e)

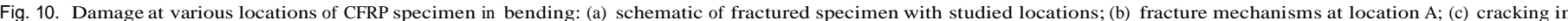

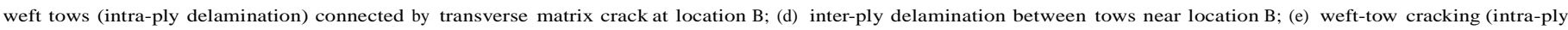
delamination) at location C. 
weft directions, respectively, at strains in the range of $5000 \mathrm{m \varepsilon}$ to $10,000 \mathrm{m \varepsilon}$ (i.e. $0.5 \%$ e $1 \%$ ). In the flexural tests of both $1.5 \mathrm{~mm}$ - and $1.0 \mathrm{~mm}$-thick specimens, the weft specimens showed earlier fracture due to lower stiffness in this direction (Fig. 8). This may also be due to the fact that the number of fibres/tows in the warp specimens is slightly more than that in the weft specimen, since they are aligned towards the longitudinal plane resisting bending more than the weft specimen. Hence, the fibre/tows straightening and stiffening effects in the warp specimens were more than those in the weft ones. Thus, the flexural strength as well as flexural modulus of warp specimens was also more than that of the weft specimens (Table 2). Here, elongation at fracture was also somewhat higher for the warp specimens. Although the tests were conducted under large-deflection conditions, this nonlinearity was not reflected in the stress-strain curves. In thin laminates, large-deflection bending causes stress stiffening, which is reflected by the stress-strain curve. According to Timoshenko and Woinowsky-Krieger [16], if the ratio of maximum deflection to plate thickness becomes greater than 0.4 and 1.0 for clamped and simply supported plates, respectively, the effect of stress stiffening should be taken into account. These stress stiffening effects, apart from the size effects, are also responsible for enhancement in ultimate flexural strength of the thinner $1 \mathrm{~mm}$-thick laminate (Table 2).

The average flexural strengths of $826 \mathrm{MPa}$ and $816 \mathrm{MPa}$ for $1.5 \mathrm{~mm}$ thick specimens in the warp and weft directions, respectively, were higher than their average tensile strengths of $762 \mathrm{MPa}$ and $764 \mathrm{MPa}$ as listed in Table 1. Several studies have highlighted that, in general, the flexural strength of a material is greater than its tensile strength [17]. This behaviour is explained as a result of the non-uniform stress distribution through the thickness of the bending specimen. In it, the maximum stress occurs only in the outermost plies and, thus, the probability of a flaw to exist within these regions of higher stresses, is lower than that for the entire specimen's cross section in a tensile specimen [18]. This can also be elucidated in terms of the stochastic variation in fibre strength, which dominates failure initiation. In the tension tests, all the fibres aligned parallel to the loading direction are subjected to a uniform stress, and so the weakest fails first. In the bending tests, only the bottom (back) plies experience the maximum tensile stress and the weakest fibres are not necessarily to be located at this region [17]. Similarly, the elongation of $1.96 \%$ and $1.9 \%$ of the warp and weft specimens, respectively, in bending was higher than their respective values of $1.55 \%$ and $1.56 \%$ in tension (see Table 1 ). This may be due to large deflections caused by flexural loads; this behaviour resulted in higher values of the Young's moduli obtained from tensile tests (Table 1). Further, usually in woven-fabric laminates, relative sliding of tows and inter-tow friction also results in a higher strain to fracture than in UD \& MD composites.

The effect of thickness on the flexural behaviour of CFRP laminates can be observed from the comparison of data for both $1.5 \mathrm{~mm}$ - and $1.0 \mathrm{~mm}$-thick specimens in Table 2. When the strength of a composite material reduces with increasing volume of the material under the same testing conditions, it is said to demonstrate a size effect. The size effect in composites is usually explained on the basis of the Weibull's statistical theory in terms of the probability of finding larger defects when the stressed volume is greater [6]. Hence, higher specimen volumes have a higher probability of having larger defects than smaller ones. Although the variation in the thickness of CFRP specimens was small, still, such an effect was manifested by them as obvious from Table 2. Here, by reducing the thickness from $1.5 \mathrm{~mm}$ to $1.0 \mathrm{~mm}$, the flexural strength of the material increased. Wisnom and Atkinson [19] found similar size effects in conducting tensile and flexural tests with various specimen sizes of unidirectional glass fibre/epoxy.
The mechanical behaviour of composite laminates is sensitive to the rate at which they are loaded; so, for their effective design, the behaviour at various strain rates should be known. Usually, the high-strain-rate behaviour of materials is characterised with a split Hopkinson pressure bar system. However, the sports products experience loadings at lower strain rates than aerospace or automotive structures and components; thus, the behaviour of CFRP onaxis laminates was investigated at various load rates to determine their rate sensitivity in a quasi-static range. This objective was fulfilled by testing 1.0 mm-thick specimens of CFRP under largedeflection bending in the warp and weft directions. The specimen's dimensions were the same as in the previous tests. Both types of specimens were tested at strain rates of $0.0417 \mathrm{~s}^{-1}$, $0.0834 \mathrm{~s}^{-1}, 0.125 \mathrm{~s}^{-1}$ and $0.167 \mathrm{~s}^{-1}$. Results for the warp and weft specimens are shown in Fig. 9. Flexural stressestrain plots for both type of specimens showed no rate-dependent behaviour. Usually, the strain-rate sensitivity of woven composites is due to inertia and strain-rate dependency of the polymer matrix. Carbon fabricreinforced composites are not sensitive to varying loading rates in the fibre-dominated modes such as on-axis specimens $\left[0^{\circ}, 90^{\circ}\right]_{2 \mathrm{~s}}$ and $\left[90^{\circ}, 0^{\circ}\right]_{2 s}$ subjected to in-plane tension, compression and bending in the low strain-rate regimes [20]. Here, the flexural tests were conducted on the on-axis laminates, which showed strainrate insensitive behaviour. However, woven CFRP demonstrates strain-rate dependent behaviour in the matrix-dominated modes, e.g. the off-axis specimens such as $[\mathrm{p} 45 /-45]_{4 \mathrm{~s}}$ layup subjected to in-plane shear [20].

The data presented in Tables 1 and 2 and Figs. 8 and 9 demonstrate that the tests were almost repeatable showing the quality of the laminates manufactured and the calibration and accuracy of the test set-up. However, for reproducibility, the data are compared with the published properties of similar materials. The CFRP material in this study consisted of TPU matrix apart from carbon T300 fibres with a fibre volume fraction of $45 \%$. Nicoletto and Riva [21] tested under tension 2/2 twill woven 8-ply 2.4 mm-thick CFRP laminates made of T300 carbon fibres having a fibre volume fraction of $42 \%$. They reported tensile strength of 800 MPa with $1.4 \%$ elongation at ultimate load. De Carvalho et al. [2] studied the tensile response of $2 / 2$ twill woven composites with T300 carbon fibres having a volume fraction of $45 \%$ using analytical and experimental methods. They found the tensile strength in the range of 560 e $650 \mathrm{MPa}$ with 1.0 e $1.2 \%$ elongation at ultimate failure. Similarly, Kim et al. [4] also reported the Young's modulus and tensile strengths of the order of $48 \mathrm{GPa}$ and $680 \mathrm{MPa}$ for twill woven CFRP laminates with fibre volume fraction of $43 \%$. It can be seen that these published results are comparable to the tensile-test data presented in Table 1; hence, the tests are reproducible. The minor mismatch may be due to differences in the type of matrix, parameters of twill woven architecture such as ends/picks count, fabric and laminate density, fibre content, crimp ratios etc. as well as specimen's size and testing conditions. However, as stated earlier, the large-deflection bending behaviour of twill woven CFRP composites was rarely studied, so no such data was found in the literature. Still, a similar trend of a lower flexural modulus than the tensile and compressive moduli, and the higher flexural strength than the tensile strength was also observed in an experimental study of 3D woven composites [22].

\section{Analysis of damage in tested composites}

As the main aim of the study is to investigate the CFRP behaviour under large-deflection bending, damage analysis of $1.0 \mathrm{~mm}$ thick warp specimens tested under bending conditions was carried out employing both the optical microscopy and X-ray micro-CT techniques. 


\subsection{Optical microscopy analysis of damage}

To investigate the damage behaviour of the specimen below the indenter and away from the loading point, samples were cut from the various locations along the length of the specimen and then polished. In this work, an OLYMPUS BX-60M microscope was used to capture the images of the through-thickness polished edges of the fractured specimen that were analysed with Image-Pro Plus software. Fig. 10 presents damage modes observed at various locations (Fig. 10a) in CFRP specimen fractured in bending. Major damage modes observed at the specimen's fractured location A (below the indenter) were inter-ply delamination between the warp tows, weft-tow cracking and fracture of fibres in the warp tows that was responsible for the final catastrophic failure, as shown in Fig. 10b. The warp tows in three bottom plies subjected to tensile load were completely fractured. At low-stress regions away from the specimen's centre (indenter), the major damage observed was longitudinal weft-tow cracking and matrix cracks. At the specimen location B, Fig. 10c shows weft-tow longitudinal cracking (intra-ply delamination) that traversed transversely through the matrix to propagate within another weft tow; thus, delamination cracks interacted through this mechanism. Here, it can be observed that damage initiation occurred at the weft tow edge (crimp location) and then propagated into the weft tow accompanied by interply transverse matrix cracking. Interlaminar delamination along the specimen's longitudinal axis due to high in-plane shear stress can also be observed in Fig. 10d near location B. Intra-ply delamination in the weft tow is also clearly seen in the microscopic image of Fig. 10e at location $\mathrm{C}$ of the specimen. Unlike the transverse cracking observed in weft tows of woven laminates under tensile loading investigated in Refs. [11,12], longitudinal cracking of these tows along the specimen's axis was found under flexural load in this study. From the microscopic analysis, it can be asserted that this cracking is the predominant damage mechanism at low-stress regions before the final failure of the laminate. Inter-ply delamination and ply fracture were the prominent damage modes at the maximum loaded regions in the specimen's centre.

Interlacing of tows in the woven laminates reduces the critical length of tows subjected to axial compression, thus decreasing the probability of fibre buckling as compared to UD laminates. However, such a failure mode still occurs under high compressive load in the woven laminates. In the large-deflection bending tests, the top ply below the indenter was subjected to compression, which resulted in fibre buckling in the warp tow aligned to the specimen's axis as shown in Fig. 11a. This failure mechanism can be seen in a form of fragmentation of fibres into short pieces in the compressed side of the specimen. Apparently, the fibres near to the specimen's neutral axis (NA) with lower compressive forces were fractured less as can be seen in Fig. 11b.

Thus, the damage mechanisms observed were: matrix cracking and inter-ply delamination, longitudinal cracking within the weft tow, tensile fibre fracture in the bottom warp tows and fibre buckling in the top warp tow under compression.

\subsection{Micro computed tomography analysis of damage}

Micro-CT was used to study three-dimensional realisations of failure mechanisms and their spatial distribution in the tested CFRP laminates at microstructural level. Micro-CT is usually employed for imaging of material's internal structure based on X-ray absorption, which is related to the material's density and atomic number [8]. A small sample with dimensions $30 \mathrm{~mm} \times 7 \mathrm{~mm}$ was prepared from the damaged region of the CFRP specimen tested under bending. The micro-CT data for the sample was collected at $58 \mathrm{kV}$ and $80 \mathrm{~mA}$. For each tomogram, 3016 radiographs were acquired with an exposure time of $1000 \mathrm{~ms}$. X-ray images were acquired from 3600 rotation views over $360^{\circ}$ of rotation $\left(0.1^{\circ}\right.$ rotation step) for $3 \mathrm{D}$ reconstruction. This reconstruction was performed with CT-Pro software, and the resulting 3D volumes were analysed using VG Studio Max 2.2 software. These settings resulted in tomograms with resolution of $11 \mathrm{~mm}$. Specifications of the system employed for CT scanning can be found elsewhere [9,10].

The reconstructed 3D images (and their 2D cross-sections) of the ultimate fracture in the $1 \mathrm{~mm}$ thick CFRP $\left[0^{\circ}, 90^{\circ}\right]_{2 \mathrm{~s}}$ specimen are presented in Fig. 12. In these images, cracks and damage were resolved based on the difference in the X-ray absorption between the carbon/TPU material and voids. Realization of damage mechanisms at the outer edge, $50 \%$ and $75 \%$ of the sample width is shown in Fig. 13a, b, and c, respectively. Apparently, before ultimate fracture, the specimen exhibited matrix cracking, and then delamination. Weak resin-rich pockets around tows acted as initiation locations for matrix cracks. These cracks were caused by shear and flexural stresses, first below the indenter, spreading then in the specimen with increase in the load. These cracks were followed by inter-ply delamination, i.e. interface cracking between individual plies, and intra-ply delamination such as tow debonding, which can be distinctively observed. Such delaminations normally appeared near the matrix-crack areas, implying that development of the cracks ensued delamination, propagating subsequently as longitudinal cracks. In woven laminates, the process of propagation of these delaminations is usually arrested by the interlacing of tows. However, the images shown in Fig. 13 are fully delaminated as they

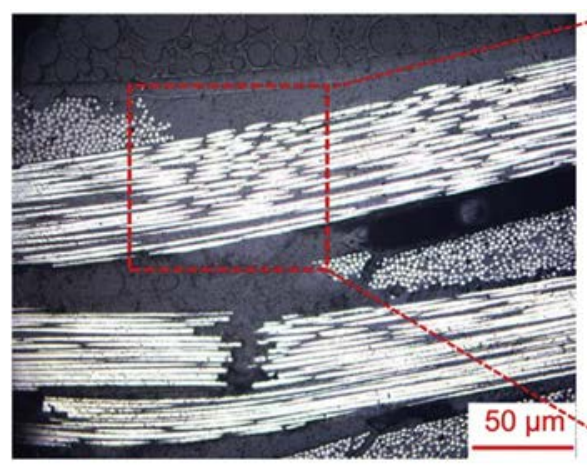

(a)

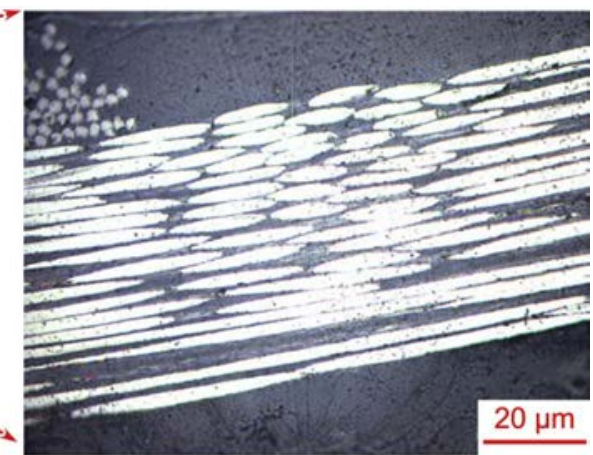

(b)

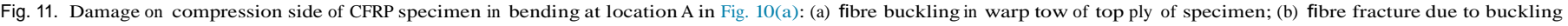
(magnified view). 


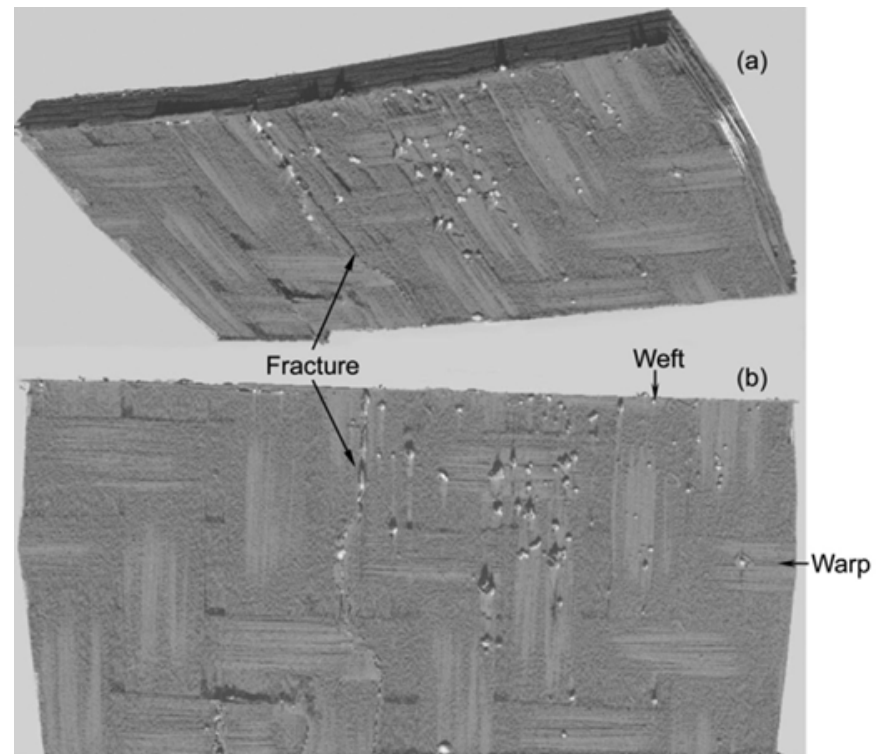

Fig. 12. Reconstructed tomographic slices of $1 \mathrm{~mm}$-thick fractured CFRP specimen (resolution $11 \mathrm{~mm}$ ): (a) damage in three-dimensional volumetric reconstruction; (b) fracture at specimen's back surface.

are for the sample taken from the highly loaded region below the indenter. In the fibre-rich regions, damage was associated with debonding of the fibre/matrix interface, which is usually caused by local stress concentrations at tow crimp in woven composites under tensile loads. Examination of the internal structure identified that almost every ply was delaminated at the time of laminate fracture. All the CT studies showed that delamination and, subsequently, ply fracture were the prominent failure modes.

Both types of microstructural analysis techniques demonstrated almost similar types of damage mechanisms in the woven CFRP specimens such as matrix cracking, delamination, tow debonding and ply fracture. Due to medium resolution and low contrast between the carbon fibres and TPU matrix, the micro-CT scans did not provide any information about the individual fibres as well as their damage such as buckling mode. Both of the methods were limited in their analysis of the full-scale tested specimens due to their fields of views restricting the size of the samples. In CT scanning, to obtain high-resolution images to observe the microstructural damage modes, a small sample is needed, while for a large-size sample, information of damage at the microstructural level is lost; hence, a

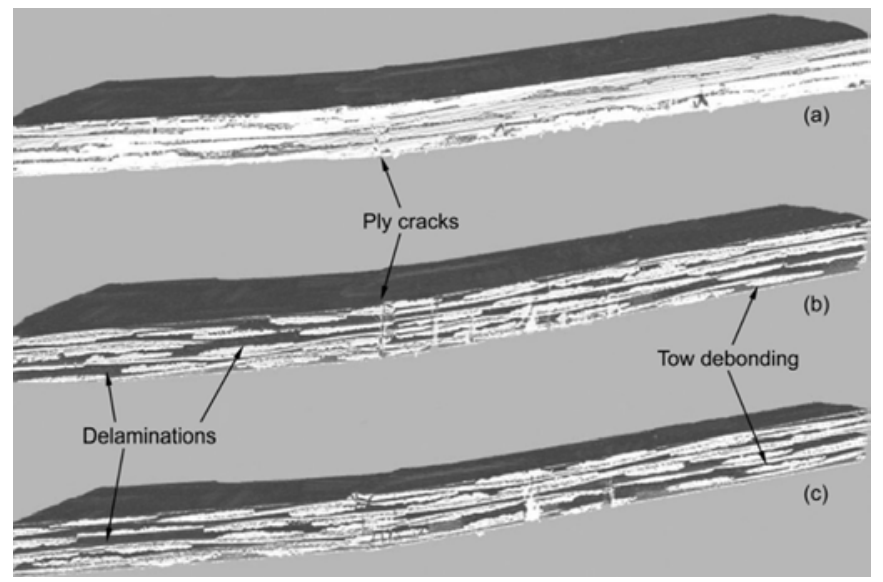

Fig. 13. Tomographic images showing damage mechanisms at various locations across width of sample (resolution $11 \mathrm{~mm}$ ): (a) edge; (b) $50 \%$ of width; (c) $75 \%$ of width. trade-off is required. Optical microscopy is time-consuming in sample preparation with a probability of introducing new damage features in the specimen during cutting and polishing. Although micro-CT provided 3D internal damage characteristics of the samples, still it took a long time for one scan to obtain the full resolution images. However, micro-CT is still preferable as it provides information about the material's internal deformation as compared to microscopy. Here, the damage analyses identified the location and type of various damage modes required for damage-tolerant design of composites and accurate modelling of their behaviour in FE simulations.

\section{Numerical simulation of damage in flexural composite specimen}

A meso-level 2D FE model consisting of homogeneous orthotropic plies and cohesive interfaces was developed in Abaqus/ Explicit to investigate damage behaviour of the fractured CFRP specimen under large-deflection bending. Cohesive-zone elements can be used to simulate delamination, fibre fracture and their interaction for assessment of multiple damage modes in composites [1]. Here, to simulate multiple delaminations at resin-rich interfaces between the individual plies in the 1 mm-thick CFRP laminate, three longitudinal cohesive layers $e$ one above the specimen's neutral axis, the second coinciding with it and the third below it e were defined. An additional transverse cohesive layer was inserted at the specimen's centre; crossing the bottom three plies, to simulate their fracture under tension and coupling between inter-ply delamination and ply fracture in the specimen, as observed in the microscopic damage analysis (see Fig. 10b). These cohesive interfaces were introduced into the model since the location of damage was identified in the damage analyses. Both the inter-ply and intra-ply cohesive layers were meshed with 4-noded bilinear COH2D4 elements. Composite plies were discretized with plane-strain reduced-integration CPE4R elements, using a mapped meshing approach. The elastic flexural and in-plane shear properties determined experimentally were assigned to the composite plies. Details of the modelling scheme, boundary conditions and damage parameters can be found in the authors' previous work [18].

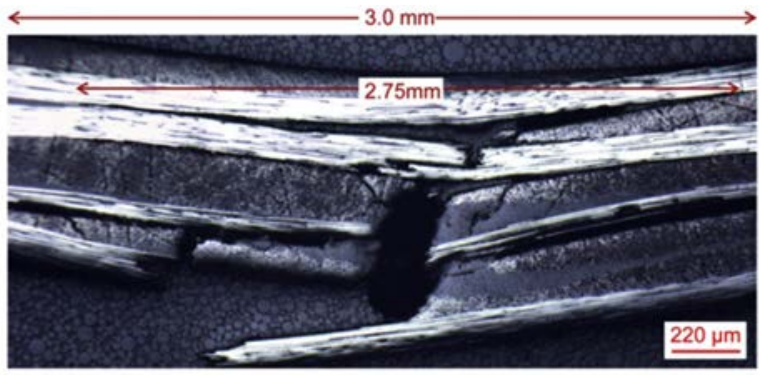

(a)

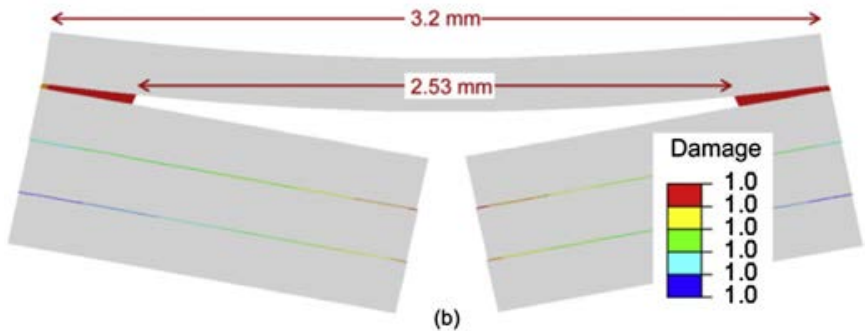

Fig. 14. Compariosn of delamination crack lengths: (a) observed in microsopic analysis of tested CFRP specimen; (b) numerically predicted with FE model (scaling factor 0.5). 


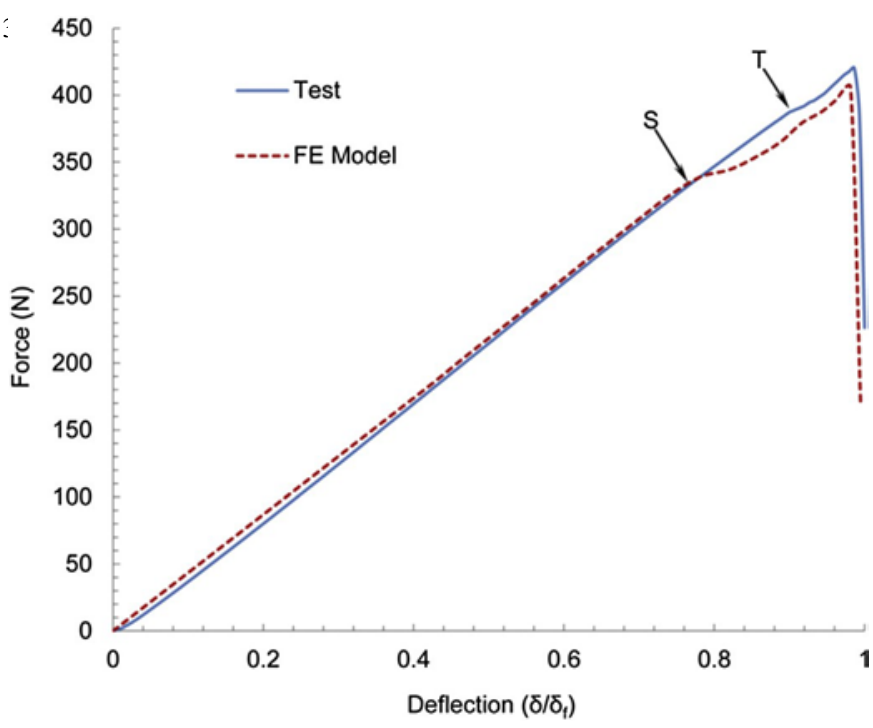

Fig. 15. Comparison of experimental and simulated load-deflection response of CFRP specimen in three-point bending.

The length of delamination cracks observed microscopically in the tested specimen is compared with that obtained numerically in Fig. 14. These lengths match reasonably well; the delaminaton length of $2.53 \mathrm{~mm}$ in simulation was somewhat smaller than $2.73 \mathrm{~mm}$ in the specimen. Here, in the simulation, only those elements which were fully damaged and deleted from the model when damage variable ' $D$ ' attained the value of unity, were considered for the crack length. However, if elements in the damage process zone with ' $\mathrm{D}$ ' levels close to 1 were also considered, then the crack length might have matched the experimental one. The numerical and experimental loadedeflection curves for the CFRP woven specimen under flexure are compared in Fig. 15, showing a good agreement. It is apparent from the plots that the forceedeflection response of the specimen was linear before the stiffness degradation started at points ' $\mathrm{S}$ ' and ' $\mathrm{T}$ ' in the simulations and test, respectively. Inter-ply delamination damage occurred at those points, represented by small drops in load. The ultimate fabric fracture in the FE model and test is identified by an abrupt load drop representing the instantaneous loss of the specimen's load-bearing capability. Both in the simulation and experiment, during delamination propagation, the specimen carried the load, but with a lower slope in the load-deflection curves indicating a loss of flexural stiffness due to delamination. Although the model catered for both geometric and material nonlinearities, the on-axis specimen consisting of only of $0^{\circ}$ and $90^{\circ}$ plies produced a nearly linear response. The FE model captured well the overall specimen's behaviour of combined delamination and ply fracture observed in the experiments. The numerical model showed a somewhat earlier stiffness degradation due to delamination, which may be because of the damage parameters defined in the model; still, the main features were the same.

\section{Conclusions}

The mechanical behaviour of woven CFRP composites was characterised by performing tensile, in-plane shear and largedeflection flexural tests under quasi-static conditions. The on-axis laminates exhibited a quasi-brittle linear behaviour before their ultimate fracture in both tensile and flexural tests. Further, they demonstrated a strain-rate insensitive behaviour while tested at various indenter speeds under large-deflection bending. A side of the specimen. Apparently, the fibres near to the specimen's and flexural properties due to the size effects and stress stiffening of thin laminates. Therefore, application of tensile material properties to study the bending behaviour of composites is not recommended. The off-axis laminates showed a nonlinear behaviour due to matrix cracking and fibre trellising in the in-plane tensile shear tests. In these tests, DIC proved to be a very useful noncontact technique to acquire full-field strain data. The obtained material data can be used for numerical simulations of the CFRP laminates under various types of loading. The tensile and flexural tests demonstrated good repeatability and reproducibility.

Damage in the fabric-reinforced CFRP laminates under largedeflection bending was studied using optical microscopy and micro-CT techniques. Microscopic analysis of damage at various locations in the fractured specimen asserted that the low-stress regions demonstrated longitudinal cracking of weft yarns, whereas the high-stress regions underwent inter-ply delamination and ply fracture. The internal damage mechanisms in the tested specimens were also investigated by means of micro-CT scanning. Here, too, considerable matrix cracking leading to tow debonding and delamination was identified along with tow/fibre breakage. In CT scanning, the internal deformation and damage of the specimen were observed without the need for cutting the specimen and lengthy polishing of specimens as in microscopy. From these analyses, the critical damage modes such as delamination and fabric fracture were incorporated in the meso-scale 2D FE model of the fractured CFRP specimen. Numerical simulations were performed to study the initiation, propagation and interaction of damage processes under large-deflection bending by employing cohesive interface elements in the FE model. The obtained numerical results agreed well with the experimental data, and the numerical model was capable to replicate the damage sequence, especially the interaction of damage modes observed experimentally in the composite specimens.

\section{References}

[1] Ullah H, Harland AR, Silberschmidt VV. Damage and fracture in carbon fabric reinforced composites under impact bending. Compos Struct 2013;101(0): 144 e56.

[2] De Carvalho NV, Pinho ST, Robinson P. Analytical modelling of the compressive and tensile response of woven composites. Compos Struct 2012;94(9): 2724 e35.

[3] Lomov SV, Ivanov D, Truong T, Verpoest I, Baudry F, Vanden Bosche K, et al. Experimental methodology of study of damage initiation and development in textile composites in uniaxial tensile test. Compos Sci Technol 2008;68(12): 2340 e9.

[4] Kim J, Shioya M, Kobayashi H, Kaneko J, Kido M. Mechanical properties of woven laminates and felt composites using carbon fibers. Part 1: in-plane properties. Compos Sci Technol 2004;64(13e14):2221e9.

[5] Ng S-P, Tse P-C, Lau K-J. Numerical and experimental determination of inplane elastic properties of $2 / 2$ twill weave fabric composites. Compos Part B Eng 1998;29(6):735e44.

[6] Wisnom M. Size effects in the testing of fibre-composite materials. Compos Sci Technol 1999;59(13):1937e57.

[7] Aymerich F, Meili S. Ultrasonic evaluation of matrix damage in impacted composite laminates. Compos Part B Eng 2000;31(1):1e6.

[8] Tan KT, Watanabe N, Iwahori Y. X-ray radiography and micro-computed tomography examination of damage characteristics in stitched composites subjected to impact loading. Compos Part B 2011;42(4):874e84.

[9] Ullah H, Harland A, Silberschmidt V. Experimental and numerical analysis of damage in woven GFRP composites under large-deflection bending. Appl Compos Mater 2012;19(5):769e83.

[10] Ullah H, Harland AR, Silberschmidt VV. Evolution and interaction of damage modes in fabric-reinforced composites under dynamic flexural loading. Compos Sci Technol 2014;92:55e63.

[11] Daggumati S, De Baere I, Van Paepegem W, Degrieck J, Xu J, Lomov SV, et al. Local damage in a 5-harness satin weave composite under static tension: Part I - experimental analysis. Compos Sci Technol 2010;70:1926e33.

[12] Gao F, Boniface L, Ogin S, Smith P, Greaves R. Damage accumulation in wovenfabric CFRP laminates under tensile loading: Part 1. Observations of damage accumulation. Compos Sci Technol 1999;59(1):123e36. 
[13] Godara A, Raabe D. Influence of fiber orientation on global mechanical behavior and mesoscale strain localization in a short glass-fiber-reinforced epoxy polymer composite during tensile deformation investigated using digital image correlation. Compos Sci Technol 2007;67(11e12):2417e27.

[14] ASTM D790e 10: standard test methods for flexural properties of unreinforced and reinforced plastics and electrical insulating materials. 2010.

[15] Bogdanovich AE, Karahan M, Lomov SV, Verpoest I. Quasi-static tensile behavior and damage of carbon/epoxy composite reinforced with 3D noncrimp orthogonal woven fabric. Mech Mater 2013;62:14e31.

[16] Timoshenko S, Woinowsky-Krieger S. Theory of plates and shells. New York: McGraw-Hill; 1970.

[17] Santiuste C, Sảnchez-Såez S, Barbero E. A comparison of progressive-failure criteria in the prediction of the dynamic bending failure of composite laminated beams. Compos Struct 2010;92(10):2406e14.
[18] Ullah H, Harland AR, Silberschmidt VV. Damage modelling in woven-fabric CFRP laminates under large-deflection bending. Comput Mater Sci 2012;64: $130 e 5$.

[19] Wisnom M, Atkinson J. Reduction in tensile and flexural strength of unidirectional glass fibre-epoxy with increasing specimen size. Compos Struct 1997;38(1):405e11.

[20] Iannucci L. Progressive failure modelling of woven carbon composite under impact. Int J Impact Eng 2006;32(6):1013e43.

[21] Nicoletto G, Riva E. Failure mechanisms in twill-weave laminates: FEM predictions vs. experiments. Compos Part A Appl Sci Manuf 2004;35(7):787e95.

[22] Dai S, Cunningham PR, Marshall S, Silva C. Influence of fibre architecture on the tensile, compressive and flexural behaviour of 3D woven composites. Compos Part A Appl Sci Manuf 2015;69(0):195e207. 